\title{
Political strategies in difficult times - The "backstage" experience of Swedish politicians on formal priority setting in healthcare
}

Peter Garpenby and Ann-Charlotte Nedlund

\author{
Journal Article
}

\section{Tweet}

N.B.: When citing this work, cite the original article.

Original Publication:

Peter Garpenby and Ann-Charlotte Nedlund, Political strategies in difficult times - The "backstage" experience of Swedish politicians on formal priority setting in healthcare, Social Science and Medicine, 2016. 163(), pp.63-70.

http://dx.doi.org/10.1016/j.socscimed.2016.06.046

Copyright: Elsevier

http://www.elsevier.com/

Postprint available at: Linköping University Electronic Press

http://urn.kb.se/resolve?urn=urn:nbn:se:liu:diva-130800

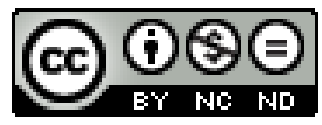





\title{
Political strategies in difficult times: The "backstage” experience of Swedish politicians on formal priority setting in healthcare
}

\author{
Peter Garpenby(1) Ann-Charlotte Nedlund $(1,2)$
}

1) The National Centre for Priority Setting in Health Care, Department of Medical and Health Sciences, Linkoping University, SE-581 83 Linkoping, Sweden

2) National Institute for the Study of Ageing and Later Life, Department of Social and Welfare Studies, Linkoping University, SE-581 83 Linkoping, Sweden

\begin{abstract}
This paper contributes to the knowledge on the governing of healthcare in a democratic context in times of austerity. Resource allocation in healthcare is a highly political issue but the political nature of healthcare is not always made clear and the role of politicians is often obscure. The absence of politicians in rationing/disinvestment arrangements is usually explained with blame-shifting arguments; they prefer to delegate "the burden of responsibility" to administrative agencies or professionals. Drawing on a case where Swedish regional politicians involved themselves in setting priorities at a more detailed level than previously, the findings suggest that the subject of "blame avoidance" is more complicated than usually assumed. A qualitative case study was designed, involving semi-structured interviews with 14 regionally elected politicians in one Swedish health authority, conducted in June 2011. The interviews were analysed through a thematic analysis in accordance with the "framework approach" by Ritchie and Lewis. Findings show that an overarching strategy among the politicians was to appear united and to suppress conflict, which served to underpin the vital strategy of bringing the medical profession into the process. A key finding is the importance that politicians, when appearing "backstage", attach to the prevention of blame from the medical profession. This case illustrates that one has to take into account that priority settings requires various types of skills and knowledges e not only technical but also political and social. Another important lesson points toward the need to broaden the political leadership repertoire, as leadership in the case of priority setting is not about politicians being all in or all out. The results suggest that in a priority-setting process it is of importance to have politics on-board at an early stage to secure loyalty to the process, although not necessarily being involved in all details.
\end{abstract}

\section{Introduction}

Resource allocation in healthcare is a highly political issue as social values will eventually determine the level of ambition and the composition of services. The political nature of healthcare is, however, not always made clear, and the role of politicians is often obscure. Still the influence of politics and politicians is prevalent as governments control the overall conditions for the setting of priorities, i.e. responsibilities and power distribution between expert bodies issuing clinical recommendations, and local commissioners left with the arduous task of identifying and executing disinvestment (Syrett, 2003; Rooshenas et al., 2015). Even when resource allocation is left to local non-elected commissioning bodies, decisions tend to be shaped by political considerations (Teng et al., 2007; Dionne et al., 2008; Smith et al., 2013). Lack of political support can, however, serve as a barrier to formal arrangements aiming at disinvestment (Robinson et al., 2011; Rooshenas et al., 2015). 
The absence of political support in rationing/disinvestment activities is usually explained with blame-shifting arguments; elected officials prefer to shift the burden of responsibility to administrative agencies or health professionals, to conceal what they expect to be unpopular and difficult decisions or to find a scapegoat, if criticism should arise. Following Weaver (1986) the blame-avoidance literature focuses almost exclusively on strategies to prevent electoral punishment. However, given the complexity of the healthcare field, where different actors seek legitimacy for their actions and where different types of actor dependencies exist (c.f. Salter, 2004; Nedlund, 2012), the role of politics and politicians, and the subject of "blame avoidance" is presumably more complicated than usually assumed and thus needs further investigation.

The political nature of priority setting in healthcare has been frequently emphasised with the argument that this process accommodates not only facts but also ideas, interest and values (Klein, 1998; Williams et al., 2012; Smith et al., 2014). Berg and van der Grinten (2003, 133) criticise attempts to downplay the political nature of allocative decisions, "the whole array of normative/political considerations linked to the question whether a treatment should or should not be available", as decisive issues risk being shifted away from the political scene to the doctor's office.

Traditionally the necessity of rationing has been solved through delegation from macro (political) to micro (clinical) level in the form of "bedside rationing" to defuse the issue (Russell et al., 2011). Another approach to "de-politicise” is to redefine health policy as a technical or scientific issue, which can be done by appointing expert bodies to advise or recommend what services should be publicly funded (Ham and Coulter, 2000; Syrett, 2003; Nedlund and Garpenby, 2014). Due to the complexity in healthcare the pure lack of clarity on who decide what has served an important function in making accountability difficult to pin down (Ham and Robert, 2003). Hence, when decision makers appear in a priority-setting context, they are typically non-elected officials or clinical leaders (Reeleder et al., 2006; Robinson et al., 2012), seldom elected representatives. Although priority setting is taking place on various levels, few politicians have adopted a distinct role in such arrangements. Few studies have investigated politicians, directly involved in priority-setting activities, who share their "backstage" experiences. Commonly the blame-avoidance literature and writings about priority setting in healthcare have a "frontstage" perspective, assuming a situation where policies have become visible and thus possible to evaluate by the public. However, the preparations before policies occur "backstage", behind closed doors and where the audience, comprising citizens and the media, is absent. In this study we focus on the "backstage", where politicians make "preparations" before policies are made public (Goffman, 1959; Wodak, 2009). We intend to show that backstage arrangements are wholly important in a situation of priority setting. When Werntoft and Edberg (2015) examine how Swedish politicians in two regional authorities perceive priority setting in general, it is far from clear whether the informants have experienced participation in a formal process and what their "backstage" experiences consist of.

Drawing on interviews with Swedish healthcare politicians, who took on the responsibility of arranging for a more limited menu in the provided health services, the aim of the study was to explore their views on how they acted "backstage", and how they experienced the new situation. By investigating how politicians behaved in actual situations when they have to engage directly with rationing, this paper will contribute to the hitherto limited knowledge on the conditions for arranging formal priority setting in a political context. 


\section{Understanding the political landscape of priority setting}

Blame avoidance as a political strategy has gained attention through Weaver (1986, 371), who argued that due to a negativity bias among voters, "politicians are motivated primarily by a desire to avoid blame for unpopular actions rather than by seeking to claim credit for popular ones”. He named a series of strategies for avoiding blame; a theme further advanced by others (e.g. Pierson, 1994). By assuming that politicians act simply to avoid electoral punishment we risk losing sight of the complexity of democratic governance in times of austerity. In the health policy arena, the subject of "blame avoidance" is presumably more complicated than usually admitted, due to the resource dependencies that exist between different categories of policy makers, elected, non-elected and clinical. Goals among politicians are not confined to the electoral or internal party arenas, but performance and implementing policies are likewise of importance. In modern democracies citizens expect politicians to act as stewards of welfare, and failing performance can easily turn into a sign of democratic deficit (Norris, 2011). A preoccupation with vote maximization and manoeuvring to avoid public blame, will hide the fact that politicians in welfare systems have to organise and reorganise for policy change under highly complex conditions.

\subsection{To create alliances across different rationales}

The issue of politics and political manoeuvres in relation to priority setting is complicated by the state of affairs in both healthcare and in democratic governance. Traditionally doctors have been providing a medical rationale for restriction in treatments, giving legitimacy to implicit rationing (Harrison, 1998). Today traditional arrangements in the health sector are being tested and the relations between government and the medical profession are more dynamic than ever. Although professionals have been challenged with new forms of medical governance (Salter, 2004), democratic governments still recognise the force of biomedical knowledge as "the most powerful and most trusted source to legitimate policies and decisionmaking in healthcare” (Kuhlmann, 2006,216). Still, politicians and professionals represent different ways of approaching problems. As emphasised by Lin (2003), in health policy various and competing types of rationales exist; scientific, which is dominated by positivist science; political, which relates to the distribution and management of power; and cultural, which refers to the norms and expectations in society (Lin, 2003). This implies that in cases of priority setting these various and competing rationales are likely to clash. As healthcare is a complex organisation it will have implications when priority setting is on the agenda, on how service areas, services and technologies are defined and divided, how the pieces are grouped and what trade-offs are made. As pointed out by Giacomini (1999) the categories used must make sense to those involved in decision-making and possibly also to key constituencies to whom the decision makers are accountable.

\subsection{The importance of leadership}

In the absence of good examples, it is far from clear what role politicians can and would like to play in a priority-setting context. In recent years the subject of leadership in relation to priority setting in healthcare has gained attention. Writing not primarily about politicians but about leadership in general in the context of priority setting, Williams et al. (2012) recognise the importance of a relational leadership. Drawing on Reeleder et al. (2006) they note that leadership needs to focus on the resolution of a disjuncture between different perspectives that exist in the healthcare organisation. Leaders of a priority-setting process need legitimacy within their own organisation, elsewhere referred to as internal legitimacy (Nedlund, 2012; Nedlund and Bærøe, 2014), as well as among external partners and the civil society (Williams et al., 2012). A relational leadership is also about mobilising support for particular actions and 
moving beyond differences to pursue activities around wider goals. One important goal is the reputation of the organisation, in our study a democratically governed needbased public health service. Robinson et al. (2012, 2388) conclude that "far from being a purely technical or procedural process, priority setting requires political acumen and skills in relationship management and coalition building, so that 'tough choices' can be made and implemented without undermining trust in the institutions". To find out what "political acumen" stands for we need more examples from real world priority-setting activities.

\subsection{Political backstage strategies}

This study illustrates the complexity of blame, as its prevention and avoidance not only concerns the relationship between politicians and voters, but also other actors. Basically the preparations backstage are of two kinds: party-political strategies and agency strategies. Wenzelburger (2011) and K€onig and Wenzelburger (2014) have made efforts to broaden the view on how politicians manoeuvre in difficult times, such as when there is an imposition of restrictions on the agenda. If politicians decide to go ahead with policies they suspect could be unpopular they will, according to Wenzelburger (2011), engage in different strategic manoeuvres. Context-specific incentives will determine what blend of strategies could be expected. In our case we name these types of strategies "party political” since they concern arrangements within and between political parties having representation in the regional health authority (Koenig and Wenzelburger, 2014). Agency strategies, i.e. organising responsibility between actors, are prominent in this respect (Hood, 2011). The strong position of the medical profession in the healthcare sector can be assumed to affect arrangements for change in this policy sector. The importance of having doctors on-board when imposing changes in the health service has been pointed out (c.f. Griffiths et al., 2000; Harrison and Mitton, 2004). What has been said above on the political strategies is not contrary to the view that politicians act to circumvent the risk of blame. Clearly such motives exist. However, Hood (2011) recognises that agency strategies serve dual purposes, not only to diffuse blame, but also to improve the governing of public services: Arrangements that provide for each of those parties to perform the tasks for which they are best fitted could be considered a formula for a marriage (if not love, at least of convenience), between blame avoidance and good policy execution in a democratic framework. (Hood, 2011, 166) Accordingly, healthcare institutional arrangements that shield one actor (politician) from blame can also contribute to a decision space among health professionals to do what they know best. Ideally a more appropriate governance of healthcare in difficult times could thus be facilitated.

\section{The context of our case}

In this paper we are focusing on one regional health authority (county council) in Sweden, which engaged in a formal prioritysetting process over a period of five months, and where politicians involved themselves at a more detailed level than previously. This health authority has 70 directly elected politicians in the County Assembly who are formally accountable to the population for the allocation of resources between service areas. In practice the 15 politicians serving on the Executive Board are in control of most political issues; among them only a handful are working full-time within politics.

Basically the priority-setting process consisted of three phases. First 90 clinical and nonclinical unit managers created a rank order among treatments and services, using a formal model with a 10- level scale where 1 indicated the highest priority and 10 the lowest. In this model each item (proposal) got its rank order from the weighting together of what was known about severity of condition, patient benefit and cost-effectiveness. Although scientific 
evidence should be used when available, the actual ranking became a matter of judgment among the professionals. The proposals for disinvestment were to be "clean", and not include efficiency measures. Targets in terms of percentages of the total net budget per provider unit were stipulated for the different phases in the process. The unit managers identified the 10 per cent of lowest ranked treatments or services, which were then allocated to professional "crossspecialty groups”. Their task was to discuss, and possibly adjust, the rank order of the proposals for disinvestment, in order to reach the target of 5 per cent of the total net budget. Their next step was to have meetings with politicians in the Priority-setting Committee (the leaders of the party groups $\mathrm{p}$ a few additional members) to inform on and discuss the proposals. In the next phase senior administrators scrutinised the list before it was handed over to the Priority-setting Committee for further reduction of the bulk of disinvestment proposals, in order to reach the final goal, disinvestments matching 3 per cent of the net budget, and thus prepare for the final decision. Eventually the remaining proposals were passed to the County Executive Board which could accept or reject them. Hence politicians were having the last word on what should be withheld from the patients/citizens, provided with lower quality, or where patient fees should be introduced.

\section{Method}

A qualitative case study was designed, involving semistructured interviews with 14 regionally elected politicians in one Swedish health authority in June 2011. Two categories of actors were recruited for the study: party group leaders (\#7) and members of the party groups (\#7). An initial meeting was held with the leaders of the party groups in April 2011. They were all members of the County Executive Board and also directly involved in the Priority-setting Committee and thus responsible for the final decisions on the setting of priorities. After the leaders had been provided with oral information on the study, their approval for participation was given. Sampling of the remaining politicians followed a stratified and convenience strategy where the party leaders were asked to suggest one member in their party group who was familiar with the priority-setting process, one of these was also a member of the County Executive Board. Hence all interviewees were members of the County Assembly and 8 of them members of the County Executive Board.

A topic guide with closed and open-ended questions on key issues was developed for the purpose of gaining information on their views and experiences of the recently concluded prioritysetting process. The first section was more descriptive. The latter sections had more open-ended questions where informants were asked to reflect on how well the priority-setting process was interrelated to other governing processes in the health authority, the partypolitical strategies and agency strategies, revealing the relation between the different actors involved in the prioritysetting process.

The interviews were scheduled in accordance with the final decision by the Priority-setting Committee. All informants gave their informal consent to participate. The interviews lasted between 30 and 70 min. The informants were encouraged to talk openly about their views of the priority-setting process throughout the interview. The topic guide had an intended flexibility and allowed for follow-up questions in order to obtain deeper understanding of the informants' experience. The interviews were conducted in Swedish by trained qualitative researchers, audiotaped with permission and transcribed verbatim. Excerpts used were translated into English by the authors. 
The interviews were analysed through a thematic analysis in accordance with the "framework approach” (Ritchie and Lewis, 2003) which allows analyses in an abductive perspective (Alvesson, 2011). Meaning the analyses were deductive, underpinned by theoretical conceptions, but also inductive, open to reflexivity and thus open to new understandings, relations and accounts that were created when generating and analysing the information. The whole process was characterised by an interpretive approach, attempting to understand the underlying accounts of their stories; what did they do, howdid they do it and whatwas the meaning behind it? (Yanow, 2000). The data analysis began by asking the question " what?'” to try to ascertain what was going on and to familiarise with the data. The coding or the indexing, i.e. the labelling and the tagging of data, started by identifying initial themes, both by reading the text line by line and in textual chunks. These initial themes were then applied to the data in order to get a view on how well the categories fit the data. The next step was to sort the data, whereby the categories and themes become refined and synthesised with others. Subsequently a framework was created, which covered both issues raised in the topic guide, underpinned by the theoretical framework, and recurring categories, informed from the data. The transcribed interview texts were read again to reflect and ensure that they corresponded to the analysis and the identified categories.

\subsection{Ethics}

As all informants were elected officials (elected to have a political opinion), and thus in compliance with Swedish legislation on ethics in research on humans (Ministry of Health and Social Affairs, 2003), ethical approval was not needed. The study was made in accordance to the guiding ethical principles for research in humanities and social science set by The Swedish Research Council. All informants were assured of anonymity and confidentiality and were requested to give their informed consent before answering the questionnaire and being interviewed. Only the research team had access to the raw data, which was protected as confidential.

\section{Results}

Results are reported in three main sections following the identified categories. The first cover the politicians' views on why they choose to engage in formal priority-setting. This is followed by a section that covers the politicians' understanding of party-political strategies related to the priority-setting exercise. The last section covers the agency strategies, i.e. how interactions between different parties developed and how the politicians view these arrangements.

\subsection{Motives for engaging in formal priority setting}

All informants recognise that the formal priority-setting process that had just been completed deviates from the conventional way of governing healthcare in their regional authority. The politicians felt they should primarily influence and control healthcare by stating broad objectives, authorising budget frames and evaluating outcomes. Hence they were supposed to govern at "arms-length" in a "new public management" fashion and thereby provide sufficient leeway for clinical management. A major problem, however, according to the politicians, was that this sort of democratic governance performed poorly in situations with strong influxes of new technologies in combination with limited resources to fund new investments. A threatening budget deficit of 300 million SEK (eqv. to 30 million EUR) and a feeling that the capability for monitoring healthcare remains poor, made the political leadership in the health authority ready to try new measures to govern the health service. Although the politicians emphasised that taking part in the priority-setting process had been fruitful and given them 
new insights, they had a lingering feeling that the budget deficit had emerged due to inability within the medical profession to take full responsibility for necessary disinvestments. Several politicians expressed dissatisfaction with the medical profession and the clinical leadership for not having “cleaned up” before expanding services.

You see there is a fair chance that we [politicians] actually take over everything too deeply and in too much detail. If we are going to do this again, because there is a lot that is good in it, then we must thoroughly consider how, at what level and how deep we should go? (I1)

I've never imagined that we as politicians should enter a process in which we have to judge every single healthcare intervention. Instead it's about ensuring that we have a system where clinical units are able to rank what they are doing. (I2)

Hence the formal priority-setting process was, according to many politicians, something they had been forced into because of inability among the professionals. Moreover, it was considered a "risky" business, meaning that they [politicians] were forced into something almost improper.

\subsection{Party-political strategies}

5.2.1. Acting in agreement across party lines

At an early stage of the process, the politicians decided to act in agreement across party lines. Hence, majority parties had chosen to deviate from the usual behaviour of meeting alone, to decide on the appropriate course of action. Instead they invited all parties to contribute to the process. This arrangement in the party-political sphere gave politicians representing minority parties an unusual opportunity to influence decisions. Informants who participated in the Priority-setting Committee held the view that a new climate of respect for different opinions had been created. The main reason for acting in agreement was to convince the medical profession that the politicians supported the process. Otherwise doctors and clinical managers might have been reluctant to come up with wellprepared proposals for disinvestments, and later to participate in committees for peer-review of those proposals.

I think it was important that everyone said the same thing and that we were agreed that it should be done and that we try to stand together. It will be like a signal system, where the politics try to signal order, security and stability in a process like this. (I2)

Precisely, that one [the professional] does a thorough job and thus one has no wish to leave it to something that just turns into a kind of political clucking. (I3)

Another reason for seeking agreement was to increase the opportunity to defend the final decisions in unity, to the public and organised patient groups.

It feels safer to do it in unity together, because then it's harder to be attacked by the patient groups, who can very clearly push their special interests. (I4)

Accordingly, to act in agreement was considered a party- political strategy having both internal and external reach.

\subsubsection{Concentrating power in the hands of the few}

Informants described the priority-setting process as being exceptionally intensive and thus extremely stressful, especially for those on the political committee who had the mandate to 
decide on disinvestments and investments. One explanation of the frustration, emphasised by some politicians, was that the process had been separated from the ordinary system of resource allocation in the health authority, and that the process required high speed decisions. In order to work efficiently under those conditions, the power to make decisions had been more concentrated than normal. The high pace of the process sometimes made it impossible to fully inform party groups. Occasionally political leaders on the Priority-setting Committee could discuss detailed proposals for disinvestments in wider party circles, but in most cases the party groups were invited to discuss only broad principles (e.g. whether to safeguard the interests of certain patient groups) and it was left to party leaders to make the final decisions.

So one cannot really say that this is a democratic process. Not in the parties, no. I firmly believe not. (I5)

The others in the groups, in our political groups, they have very little idea of what it's about. Very little. (I6)

Thus some of the informants felt they lacked information, since they had to transfer most of the decision power to their leaders, who in turn regarded the elitist arrangement as necessary in the circumstances.

\subsubsection{Avoiding controversy}

Among the politicians there was a noticeable divide between those who saw their role as facilitating the process by adhering to the professional judgments on the "proper" rank order for disinvestment, and those who saw their role as safeguarding welldefined patient groups even at the cost of disrupting the process. It was felt by some to be a matter of prohibiting the tendency to pit patient groups against each other and protect vulnerable groups.

Some things are of course uncomplicated. Like stopping selling something or if you're talking about travel vaccination, that's one thing. But then when it's about groups, or about children, that is when I experience it to be very big ... and we ... there is something in common one doesn't want to do something that threatens to affect a vulnerable group. (I7)

But that is the responsibility yes, the role you should play as a politician. To see the big picture and see groups. Children and older people, mentally weak e so how are they going to be affected by these proposals? But when you are involved in judging certain surgical operations it's hard to see [what your role is]. (I8)

If a disinvestment proposal proved to be too controversial and was thus threatening the consensual atmosphere, the preferred solution was to drop it. Examples of disinvestment proposals mentioned by the informants that were rejected for this reason were, for example, the removal of a second home visit by midwives to first-time mothers, the reduction of ambulance services in rural areas and the reduction of the number of patient referrals to private contractors in sport's medicine, arguing the prevention of "overconsumption" of publicly funded healthcare. In the latter case the position of majority parties and part of the opposition was totally contradictory and threatened political unity. To resolve this conflict majority parties agreed to forward the case to a list of proposals that should be handled separately in due course.

Politicians indicated that this type of formal process did not really allow for discussions on important matters that could enable major savings, but at the same time were highly sensitive: 
removing treatments of limited marginal benefit to patients in service areas like intensive care or cancer treatments for example.

It could perhaps have been more relevant to take a stand on forth line cancer treatment. They...that is, that one raises issues and restructures them a bit to be able to get the political relevance of the questions (I8)

...you can't like take away budget funds or look at it as a way to earn money. But it's a completely different, bigger discussion, that one must bring a little caution and kind of respect to. (I2)

Important issues were put aside for later consideration. Thiswas not due to any conflict between political parties. Instead, they felt that not enough time was available for politicians to familiarise themselves with issues that would have required more thorough discussions before a decision could be made.

\subsection{Agency strategies}

5.3.1. Creating an alliance with the medical profession

One important reason for interacting with professionals was that this gave politicians an opportunity to demonstrate that they were ready for tough decisions. In the past politicians had been criticised by clinical leaders for not taking enough responsibility for the resource allocation process, especially in cases when disinvestment decisions proved necessary. By appearing in front of clinicians they hoped to display that the health authority had moved into a new era.

According to the politicians yet another reason for interacting more closely with the medical profession was to counteract unwanted tendencies, noticed in the past in relation to resource allocation. Dissatisfied professionals could easily blame the politicians for undesirable changes in the health service and thereby confuse both decision-making and implementation. By letting the profession feel responsible for priority setting, the politicians hoped to prevent opposition and the occurrence of an "us and them" situation. To have clinical units and clinicians on board also freed the politicians from having to take sole responsibility for difficult decisions. If criticised they could always claim that priority setting was a joint responsibility between politicians and the clinicians, and that they had the role of judging disinvestment proposals originating from the clinical units. This made the politicians feel more confident but at the same time dependent on the professional judgments on disinvestment.

We implement what they [unit managers] have decided. That's just how it is. (I3)

I'm very much in their hands. It's so ... ... but I feel fairly safe when I think that they [unit managers] have met in those large groups, crossover [peer-review] groups. (I6)

Those among the politicians who had been involved in a dialogue with clinical managers explained that it had contributed to a better understanding of the content of disinvestment proposals, and made them feel more secure and confident in their own decision-making. Another important motive for meeting with clinical leaders was to "read the situation" in the clinical units, as some of the units like cancer, neurology and cardiology seemed confident of their disinvestment score while others, such as geriatric care and psychiatry, signalled more uncertainty on the rights and wrongs. Politicians found this information important when 
deciding on particular disinvestments. Also informants who questioned the wisdom of having politicians decide on clinical matters said they had benefited from meeting with the clinicians.

We could never have come to a decision if we had not met all units and gone through every suggestion. (I7)

I would state that we have a very, very good grip on how it looks in reality. Also what it is that is needed ... where the needs lie and so on. We get a very transparent health service. (I1)

Hence informants hoped that the priority-setting process had contributed to a higher degree of respect between the political and professional domains.

\subsubsection{Establishing a working interface between health system actors}

Although all informants emphasised the important role of senior administrators in the process, the political leaders of the majority parties specifically expressing confidence in the administrative support, it became obvious that tensions had arisen as a result of how the process had been designed. The opposition leaders in particular highlighted some of the drawbacks of the process, for example the risk of creating a blurred interface between politics, administration and clinical leadership. The politicians appreciated the interaction with clinical leaders where they could obtain information on proposals for disinvestment, and were given an opportunity to discuss with clinicians. Problems occurred when politicians felt they had reached an informal agreement with the profession on how to rank certain items for disinvestment, and administrative leaders had intervened to make changes in this order. In those cases, some of the politicians felt strongly that this could disrupt the confidence of clinical leaders that they had established.

But it was just that ... there were suggestions of different priorities than what one had agreed upon in these [professional] "cross-groups" ... And that was a little surprise. That caused a little concern for us politicians....That is to say, this managerial group, the management in this county had poked about at these in the end, and made some changes ... This was not directly sanctioned by the units that had been involved in this crossgroup. And it became a bit tough for them [unit managers] to present something that they did not really recognise ...

Then there was psychiatry, geriatric, and disability. And then they had changed the information and hadn't told those who were going to present it to us. So when they [unit managers] stood there then and were going to start, they said: "What is this? We had a one there, and now it is a seven!” ... So, it was just that ... I could have gone through the roof because they are treated badly in every other way. (I10)

As the formal model for determining the rank order of proposed disinvestments served as an important vehicle throughout the entire priority-setting process, it had implications for how the politicians could exercise their influence. Discussions among politicians, but also the actual decision-making, were to a high degree guided by the rank order proposed by the clinical and non-clinical unit leaders. Informants explained that early on in the process the politicians decided not to challenge proposals for disinvestment scoring of six or above. Consequently, decision-making was dependent on the politicians' ability to reach unity on the "deprioritised" low ranking items: those ranked as nine or ten. More intense discussions centred round items scoring seven or eight on the list. It was at this level that politicians saw an opportunity to make extra savings e if they could reach unity. 
It's difficult to "deprioritise” something that a clinical unit representative says is very important for this patient group. (I2)

It's clear that what the units have prioritised, such as nines for example, yes but then we sort of felt that this is what they accepted. A nine. And then one has got to almost automatically accept it. (I5)

There were three reasons why informants had doubts on the design of the priority-setting process in relation to their role as politicians. Firstly, the proposals on disinvestment coming from the units were in most cases at too low a level of detail, i.e. the health service had been broken up where the estimated savings were as little as 20,000 SEK (compared to the health authority's total budget for healthcare of approximately 6 billion SEK). Some politicians saw this as misuse of their time as they had to spend hours in meetings to get aquatinted with all the proposals in the list for disinvestment.

And sure, small streams make great rivers. Because we're haemorrhaging money, that's just how it is. But spending 20 minutes' discussion on a small matter, which perhaps gives 20,000 more or less, that's not right, I think. (I19)

On the other hand, some thought that the design of the process, where large numbers of proposals for disinvestment where handled, paved the way for political unity. Since most of the proposals involved small sums of money, the politicians found it easier to reach agreement, compared to a situation when large sums had been at stake.

Secondly, many politicians found a lack of "politics" in the vast material they had to deal with. Some saw this as the price they had to pay to safeguard collaboration with the clinicians, i.e. politicians had to accept their role in the current arrangement. Other informants regarded the absence of "politics" as the result of improper design of the process; something that had to be rectified if it was to be repeated. They thought that a priority-setting process involving politicians should focus more on what was political and leave the rest to the medical profession to decide.

Of 1022 decisions there were actually 2 of them that concerned the standing down of ambulance stations inland, which I perceived as political. (I8)

There are really few questions that are [political], those questions... yes, but grants for glasses for children is a political question. Fees are yes a political question. But few of these questions are specifically political. (I10)

Thirdly, an important feature of the priority-setting process was the bringing together of numerous proposals from the clinical units representing all specialities into a common template for rank order. Some politicians felt uncomfortable carving up healthcare, causing them to lose sight of the big picture.

Shall we spend resources to extend the life two, three weeks, up to a month? Or shall we spend money instead on helping somebody that has an illness, which means that they might avoid a handicap? We will be forced to take these types of decisions!!! (I11)

The requirements to deal with too many disinvestment proposals in too short a time made some politicians feel they had departed from what they, as elected representatives, should 
really concentrate on and discuss: ethical issues, holistic thinking about health services and the importance of considering the efficiency of care pathways in the healthcare system.

\subsubsection{Imposing neutrality in the process}

Politicians described their major role as enabling a process that should primarily speed up the interaction within the medical profession. At least some recognised that they had a leadership role, but more in inspiring terms in relation to the medical profession.

Informants described a situation where they had to manoeuvre carefully to make the clinical units act in favour of the prioritysetting process. Hence politicians had to impose neutrality in the process between the clinical units, also taking into consideration that some units might have less skill in handling the scoring, contributing to poorer quality of disinvestment proposals. The political leadership should, according to informants, encourage all units to contribute with no-one standing outside of the process.

I think that maybe we have to engage with the units which have not been so successful in prioritising, a little more targeted. Because it's not a good signal if those units which are not as good at it (at setting priorities), somehow get away with it, or whatever, and don't have to prioritise so much. (I2)

I mean, clearly one can see differences between the units. Those major units, cancer, neuro and the cardiac centre _ _ _ to them disinvestments was no big issue actually.____Compared to those who are dealing with the elderly and mental health and the others who don't have development in the same way, and clearly it is then more difficult for them to prioritise as well. And this was visible in their presentations and so forth. It's clear that it meant that we toowere unsure of getting into those areas. (I1)

One important aim of the process was thus to enable, for increased peer-review of disinvestment, proposals within and between service areas. Although most politicians saw this element as vital, especially as they themselves did not feel capable to judge all clinical details, it could have adverse effects on the process. Informants suspected that the hierarchy among medical specialities and the ability among clinical managers to argue their case could disrupt the result. Neutrality between clinical leaders representing the various specialities could not be guaranteed and thus the process was cementing established medical hierarchies. Especially among politicians, who saw their role as safeguarding the interest of certain groups of patients, there was a feeling that the design of the process might disadvantage certain medical specialities and their patients.

\section{Discussion}

This paper illustrates what happens when politicians feel pressured to delve directly into a process of rationing. They went as far as unburdening the non-elected officials and clinicians' part of the responsibility for the final decision making on the withdrawal or restriction of services. Several strategies can be distinguished which became important to politicians when placed in the situation of having to take on an active role. To appear united and to suppress conflict was an overarching strategy on the party-political scene, which served to underpin the vital agency strategy of bringing the medical profession into the process. A key finding is the importance that politicians, when appearing "backstage”, attach to the prevention of blame from the medical profession. Obviously politicians care about how policies are received by their electorate, but among healthcare professionals are such powerful opinion leaders that it 
is necessary to control their reactions. Thus when disinvestment was on the agenda it became important to avoid blame from professionals, to secure their appraisal skills and facilitate changes in programmes and services (Griffiths et al., 2000; Harrison and Mitton, 2004). Hence the politicians in our study focused mainly on "internal legitimacy" (Nedlund, 2012; Nedlund and Bærøe, 2014), what Williams et al. $(2012,113)$ call "legitimacy within the organizational context”. They were promoting the reputation of the organisation vis-a-vis the medical profession by suppressing partypolitical conflict, and building partnerships with the profession. Although the politicians in this study seem to have appreciated the opportunity of dialogue with clinical leaders, allowed by the formal priority-setting process, there are indications of dissatisfaction with the experienced situation. Firstly, politicians felt they had to assume responsibility by taking on an active role in rationing, mainly due to the inability within the medical profession to execute disinvestments, in order to balance new investments in healthcare. Secondly, having accepted their new role because of a soaring budget, politicians felt trapped by a process that in many respects failed to match their expectations. Being in an alliance with the clinical leaders made politicians dependent on the professionals' judgments and some felt uneasy with this limited role. Thirdly, politicians requested more politics in the many proposals on potential disinvestments that landed on their desks. Fourthly, the core feature of the process to carve up the health service e in order to create a comparable rank order e caused politicians to feel they had lost the necessary overview.

While the allocation of resources in publicly funded healthcare in manyways concerns social values and politics, the politicians felt uncomfortable when they were placed in a situation of having to judge clinical details in the many proposals for disinvestment. For the politicians having to consider a mass of detailed proposals, the situation reminds one of "a technocratic chastity belt" (Klein, 2010). The template for creating the rank order was designed to fit a medical rationale and this way of handling resource allocation did not entirely make sense to the politicians (c.f. Giacomini, 1999; Lin, 2003).

Some ambiguities appear in the interviews, such as when the politicians on the one hand prefer doctors to take more responsibility for disinvestments, while on the other demonstrate an awareness of the many difficult decisions just around the corner. All those issues that politicians obviously recognise as political but where further discussions with professionals prove important. One might add that which issues are political or not political is difficult to distinguish beforehand, as this is very much dependent on context and timing. Faced with future difficulties that the current process did not address, the politicians in the study seem to request a new type of partnership with the medical profession.

Drawing on our findings, the crux of the matter seems to be to create necessary leeway for politics without forcing politicians too deeply into a world where healthcare is carved up by a mass of clinical details, meantime securing the willingness among clinical leaders to take further responsibility for resource allocation including disinvestments. We concur with Hood $(2011,166)$ that although blame avoidance is part of the reality, the division of tasks in healthcare could be regarded as "good policy execution in a democratic framework" and not necessarily a way to escape responsibility. Neither the need for greater political support for explicit rationing/disinvestment (Rooshenas et al., 2015) nor priority setting with political acumen (Robinson et al., 2012) requires perfunctory political involvement in the process. However, as politics is always present in resource allocation, efforts to bypass politics and politicians by requesting more "rationality" in the process, is not the solution. The critique that political interference causes "disruption" in the priority-setting process often stems from 
a situation where politicians are not present when they should be, and enter the process haphazardly and at too late a stage.

There are many studies supporting the view that a well-defined process and decision tools to guide disinvestment would be of great help in priority setting (Robinson et al., 2012; Rooshenas et al., 2015). Our study underlines the importance of having politics onboard at an early stage to secure loyalty to the process, but not necessarily being involved in all details. Since healthcare systems differ between countries, we cannot simply infer from an individual case in one specific context on "how things are'. However, our findings do indicate that a process designed for, and which make sense to professionals, is not self-evidently apt for politicians. Something that is probably not restricted to a regionalised system - as in the current case - but seems valid in every democratic healthcare context. We need more country specific studies as well as comparative ones on the role of politics and politicians in prioritysetting arrangements.

Obviously the politicians in this study did recognise a need for dialogue with the medical profession on difficult and ethically sensible issues, for which there was little room in the current process. Our case illustrates that one has to take into account that priority settings requires various types of skills and knowledges - not only technical but also political and social. This might be achieved in various ways, dialogue involving a broad range of actors politics, professionals, interest groups and citizens - is vital for generating legitimacy for both process and results. Another important lesson from our study points toward the need to broaden the political leadership repertoire (Sørensen, 2006), as leadership in this case is not about politicians being all in or all out. The political repertoire in priority setting should include dialogue with important stakeholders but could also comprise new forms of arm's length bodies or various “mediating institutions” (Tenbensel, 2002; Nedlund, 2012), which could possibly handle difficult matters both frontstage and backstage. At the heart of priority setting lies the question of "who gets what, when and how", [author italics], as superbly framed by Lasswell (1936), which is indeed value-laden and only by acknowledging the political in priority-setting and rationing, can we enhance the processes of making just and legitimate priorities in a democratic context.

\section{References}

Alvesson, M., 2011., Interpreting Interviews. Sage, London.

Berg, M., van der Grinten, T., 2003. The Netherlands. In: Ham, C., Robert, G. (Eds.), Reasonable Rationing: International Experience of Priority Setting in Health Care. Open University Press, Maidenhead, pp. 115-140.

Dionne, F., Mitton, C., Smith, N., Donaldson, C., 2008. Decision maker views on priority setting in the Vancouver Island health authority. Cost Eff. Resour. Alloc 6, 13.

Giacomini, M.K., 1999. The which-hunt: assembling health technologies for assessment and rationing. J. Health Polit. Policy Law 24 (4), 715-758.

Goffman, E., 1959. The Presentation of Self in Everyday Life. Doubleday, New York. 
Griffiths, S., Reynolds, J., Hope, T., 2000. Priority setting in practice. In: Coulter, A., Ham, C. (Eds.), The Global Challenge of Health Care Rationing. Open University Press, Buckingham, pp. 203-213.

Ham, C., Coulter, A., 2000. Conclusion: where are we now? In: Coulter, A., Ham, C. (Eds.), The Global Challenge if Health Care Rationing. Open University Press, Buckingham, pp. 233-250.

Ham, C., Robert, G., 2003. Conclusions. In: Ham, C., Robert, G. (Eds.), Reasonable Rationing: International Experience of Priority Setting in Health Care. Open University Press, Maidenhead, pp. 141-156.

Harrison, S., 1998. The politics of evidence-based medicine in the UK. Policy Polit. 26 (1), 15-31.

Harrison, A., Mitton, C., 2004. Physician involvement in setting priorities for health regions. Healthc. Manag. Forum 17 (4), 21-27.

Hood, C., 2011. The Blame Game. Spin, Bureaucracy, and Self-preservation in Government. Princeton University Press, Princeton.

Klein, R., 1998. Puzzling out priorities, why we must acknowledge that rationing is a political process. Br. Med. J. 317, 959-960.

Klein, R., 2010. Rationing in the fiscal ice age. Health economics. Policy Law 5 (4), 389-396.

König, P., Wenzelburger, G., 2014. Toward a theory of political strategy in policy analysis. Polit. Policy 42 (3), 400-430.

Kuhlmann, E., 2006. Modernising Health Care: Reinventing Professions, the State and the Public. Policy Press, Bristol.

Lasswell, H.D., 1936. Politics: Who Gets What, When, How. Whittlesey House, McGrawHill, New York.

Lin, V., 2003. Competing rationalities: evidence-based health policy. In: Lin, V., Gibson, B. (Eds.), Evidence-based Health Policy: Problems and Possibilities. Oxford University Press, Melbourne, pp. 3-17

Ministry of Health and Social Affairs, 2003. Government Bill. The Act Concerning the Ethical Review of Research Involving Humans. Prop 2003:46.

Nedlund, A.C., 2012. Designing for Legitimacy: Policy Work and the Art of Juggling when Setting Limits in Health Care. Linköping University Electronic Press, Linköping.

Nedlund, A.C., Garpenby, P., 2014. Puzzling about problems: the ambiguous search for an evidence-based strategy for handling influx of health technology. Policy Sci. 47 (4), 367-386. 
Nedlund, A.C., Bærøe, K., 2014. Legitimate policymaking: the importance of including health-care workers in limit-setting decisions in health care. Public Health Ethics 7 (2), 123133.

Norris, P., 2011. Democratic Deficit: Critical Citizens Revisited. Cambridge University Press, New York.

Pierson, P., 1994. Dismantling the Welfare State? Reagan, Thatcher, and the Politics of Retrenchment. Cambridge University Press, Cambridge.

Reeleder, D., Goel, V., Singer, P.A., Martin, D.K., 2006. Leadership and priority setting: the perspective of hospital CEOs. Health Policy 79 (1), 24-34.

Ritchie, J., Lewis, J., 2003. Qualitative Research Practice: a Guide for Social Science Students and Researchers. Sage, London.

Robinson, S., Dickinson, H., Freeman, T., Williams, I., 2011. Disinvestment in health e the challenges facing general practitioner (GP) commissioners. Public Money \& Manag. 31 (2), 145-148.

Robinson, S., Williams, I., Dickinson, H., Freeman, T., Rumbold, B., 2012. Priority-setting and rationing in healthcare: evidence from the English experience. Soc. Sci. Med. 75 (12), 2386-2393.

Rooshenas, L., Owen-Smith, A., Hollingworth, W., Badrinath, P., Beynon, C., Donovan, J.L., 2015. I won't call it rationing...: an ethnographic study of healthcare disinvestment min theory and practice. Soc. Sci. Med. 128, 273-281.

Russell, J., Greenhalgh, T., Burnett, A., Montgomery, J., 2011. No decisions about us without us? Individual healthcare rationing in a fiscal ice age. Br. Med. J. 342 (7812), d3279.

Salter, B., 2004. The New Politics of Medicine. Palgrave, Basingstoke.

Smith, N., Mitton, C., Bryan, S., Davidson, A., Urquhart, B., Gibson, J.L., Peacock, S., Donaldson, C., 2013. Decision maker perceptions of resource allocation processes in Canadian health care organizations. A national survey. BMC Health Serv. Res. 13, 247.

Smith, N., Mitton, C., Davidson, A., Williams, I., 2014. A politics of priority setting: ideas, interests and institutions in healthcare resource allocation. Public Policy Adm. 29 (4), 331347.

Syrett, K., 2003. Technocratic fix to the "legitimacy problem”? The Blair government and health care rationing in the United Kingdom. J. Health Polit. Policy Law 28 (4), 715-746.

Sørensen, E., 2006. Metagovernance: the changing role of politicians in processes of democratic governance. Am. Rev. Public Adm. 36 (1), 98-114.

Tenbensel, T., 2002. Interpreting public input into priority-setting: the role of mediating institutions. Health Policy 62 (2), 173-194. 
Teng, F., Mitton, C., MacKenzie, J., 2007. Priority setting in the provincial health service authority: survey of key decision makers. BMC Health Serv. Res. 7, 84.

Weaver, R.K., 1986. The politics of blame avoidance. J. Public Policy 6 (4), 371-398.

Wenzelburger, G., 2011. Political strategies and fiscal retrenchment: evidence from four countries. West Eur. Polit. 34 (6), 1151-1184.

Werntoft, E., Edberg, A.K., 2015. Swedish politicians' view of obstacles when dealing with priority settings in health care. J. Health Organ. Manag. 29 (4), 532-542.

Williams, I., Robinson, S., Dickinson, H., 2012. Rationing in Health Care: the Theory and Practice of Priority Setting. The Policy Press, Bristol.

Wodak, R., 2009. The Discourse of Politics in Action: Politics as Usual. Palgrave Macmillan, Basingstoke.

Yanow, D., 2000. Conducting Interpretive Policy Analysis. Sage, London. 